\title{
Distribution of Heavy Metals in Soils in the Vicinity of the Proposed Mkuju Uranium Mine in Tanzania
}

\author{
Firmi P. Banzi ${ }^{1}$, Peter K. Msaki ${ }^{1} \&$ Najat K. Mohammed ${ }^{1}$ \\ ${ }^{1}$ Department of Physics, University of Dar es Salaam, Tanzania \\ Correspondence: Firmi P. Banzi, Department of Physics, University of Dar es Salaam, P.O. Box 35063, Dar es \\ Salaam, Tanzania. E-mail: fpbanzi@yahoo.com
}

Received: May 1,2015 Accepted: May 26, 2015 Online Published: June 28, 2015

doi:10.5539/ep.v4n3p42 URL: http://dx.doi.org/10.5539/ep.v4n3p42

\begin{abstract}
Tanzania is at advance stages in the preparation to start uranium mining at Mkuju River Deposit. In order to implement best practice in environmental management in uranium mining as required by national and international regulations and standards, a set of site specific baseline data have to be established prior the mining operation. In order to establish heavy metal baseline data for this purpose, a total of 84 soil samples were collected from clustered area of about $1,300 \mathrm{~km}^{2}$ at two depths: $0-15 \mathrm{~cm}$ and $15-30 \mathrm{~cm}$. Analysis of the data using EDXRF showed a total metal concentration ranges of 3570-19400 for Al, 15200-58600 Fe, 400-1400 Mn, 15.2-54.9 Cr, 13.5-51.0 Zn, 2.2-45.3 Pb, 2.1-37.3 Cd, 0.2-23.0 Hg, 1.8-25.1Cu, 2.1-22.7 $\mathrm{Ni}$ and 0.8-9.1 $\mathrm{mgkg}^{-1}$ for Co. Since the spatial distributions of heavy metals in the vicinity of the planned uranium mine are comparable to established global concentration ranges in soils, it is an indication that the distribution is natural. By virtue of their strong association with uranium and immobility in soil, spatial distributions of lead and copper concentrations would be more sensitive indicators for monitoring uranium related soil contaminants when the uranium mine become operational.
\end{abstract}

Keywords: baseline, best practice, heavy metals, Mkuju river

\section{Introduction}

The toxicity and tolerance limits of heavy metals are well documented and in many cases they have been used in formulation of national or international standards (Tricopoulos, 1997; EU, 2002; USEPA, 2002; Cheng et al., 2006; TBS, 2007; Momodu \& Anyakora, 2010; Jintao et al., 2011; Lokeshappa et. al., 2012). By definition, tolerance limits are expressed in terms of exposures above background levels. For this reason verification of compliance with tolerance limits requires knowledge of natural background distribution for comparison. When established prior to the commencement of mining operations, the background distribution is called baseline data for the mining in that specific area (Ming et al., 1999). Unfortunately, baseline data are site specific and their accurate establishment prior to planned activity can be very demanding for various reasons. First, the area for which the baseline data has to be established can be very extensive and therefore sampling and data processing needed to reproduce a good representation of the spatial and temporal distributions of the area is challenging. Second, for data to be a good representative of a point, soil sampling is done by taking samples at least two layers. This approach makes it possible to establish data base for mobile and immobile heavy metals (Swenson et al., 1984). Third, for the sake of accuracy, duplicates or triplicates of analyses have to be made for each sample taken. If all these requirements are taken into consideration, establishment of baseline data can be costly and time consuming. In this work a method to reduce sampling points without sacrificing spatial and temporal distribution representation of concentration of heavy metals in soil at Mkuju river basin is presented.

\section{Materials and Methods}

\subsection{Selection of the Study Area and Sampling Points}

Mkuju river basin is hosting a viable uranium project namely Mkuju River Project (MRP). The MRP is located in the Southern part of Tanzania between latitudes $9^{\circ} 45^{\prime}$ to $10^{\circ} 30^{\prime} \mathrm{S}$ and longitudes $30^{\circ} 30^{\prime}$ to $37^{\circ} 00^{\prime} \mathrm{E}$ in Namtumbo district, in Ruvuma region (MSL, 2011). The study area consisting of the area within the MRP and the surrounding area likely to be affected by the project is shown in Figure 1. The MRP area covers about 3000 $\mathrm{km}^{2}$ (MSL, 2011) and the area to be affected around the MRP was estimated by AERMOD dispersion model. 
This model uses particles characteristics, meteorological factors and topographical characteristics of the terrain of the area as inputs and drift distance as output (Pasquill \& Smith, 1983; Marticorena \& Bergametti, 1995; Holmes \& Morawska, 2006). In this study the boundary of the area to be affected by the mining process was demarcated by decreasing the drift distance from the maximum value of $5 \mathrm{~km}$ downwind by $0.5 \mathrm{~km}$ for consecutive 30 degrees to a minimum drift distance of $2 \mathrm{~km}$ upwind predicted by the model. As a result an area of about $1300 \mathrm{~km}^{2}$ was formed round the project boundary. This area includes the already populated villages of Likuyu-Sekamaganga, Mtonya in Namtumbo district and the Selous wildlife world heritage.

In principle, for data collected from a contaminated area to be a representative distribution of contaminants in the area, a square grid of $10 \mathrm{~m} \times 10 \mathrm{~m}$ has been used in previous studies (NRC, 1992). When related to the study area of $1300 \mathrm{~km}^{2}$, estimated in this study, this sampling approach would require enormous amount $\left(2 \times 10^{8}\right)$ of sample points. Since this study aims at establishing baseline data whose distribution varies slowly with distance, the grid was increased to $100 \mathrm{~m} \times 100 \mathrm{~m}$ to reduce the sampling points without sacrificing representation of heavy metal distributions. Further reduction was achieved by grouping the area in regions with similar soil taxonomy (FAO, 1988) in combination with aerial photographic and topographic maps obtained from the Ministry of Agriculture (private communication). With this approach the study area was divided into 42 clusters of sampling plots shown in Figure 1. The number of samples $(\mathrm{n}=84)$ was then calculated at a confidence level of 95\% according to the equation 1 (Santos Santos et al., 2006).

$$
n=\frac{Z a^{2} p(1-p)}{d^{2}}
$$

Where $\mathrm{Za}^{2}$ is $1.96, \mathrm{p}$ is a proportional value at 0.05 and $\mathrm{d}$ is a precision factor $8.5 \%$.

\subsection{Sample Collection and Packing}

Prior to sample collection, organic material and debris were removed. A $25 \mathrm{~mm}$ diameter stainless steel soil auger was marked at height of $15 \mathrm{~cm}$ and $30 \mathrm{~cm}$ to determine precisely the sequential depth intervals of the samples being collected. The auger was pushed straight down into the soil to the desired depth when the samples were removed. The samples were removed from auger using a stainless steel rod. Before moving to a different plot, the auger and stainless steel rod were thoroughly cleaned with light brush to remove any soil from the previously sampling plot.

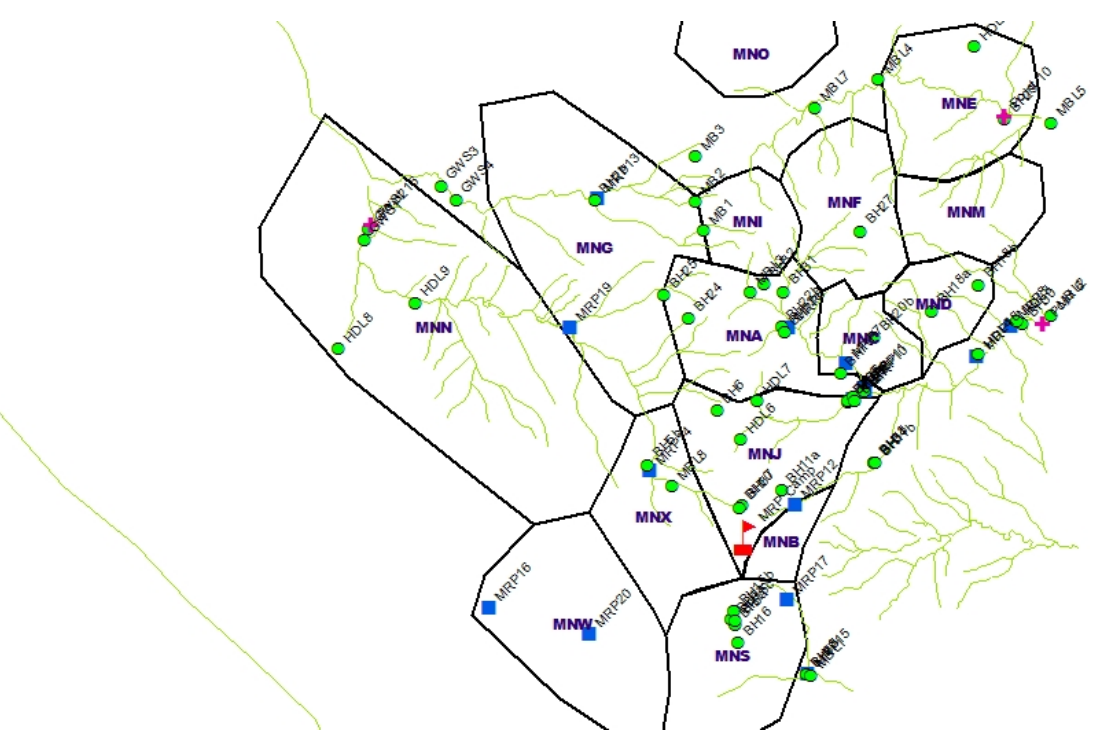

Figure 1. Map of the MRP showing the sampling locations

Three subsamples were taken randomly at each layer from different points of each plot. The subsamples with similar depths were homogenized to acquire a composite from which a representative sample for the depth in a plot was drawn. At each sampling plot, replicate samples were collected from depth range: 0 to $15 \mathrm{~cm}$ to represents metals retained in the topsoil and from depth range: 15 to $30 \mathrm{~cm}$ to represents metals in the subsoil. In addition, four points in the concession area were also selected and sparsely sampled to produce data for future 
rehabilitation. All the sampling plots in Figure 1 were geo-referenced using a global positioning system (GPS). The collected samples were placed each in a separate clean zip top polyethylene bag, sealed and legibly labeled with sample date, plot number and soil depth before stored for subsequent transportation to the analytical laboratory.

\subsection{Sample Preparation}

The samples were oven dried at $100^{\circ} \mathrm{C}$ for 24 hours to reduce its moisture content until constant weight was achieved. Each sample was ground into fine powder using an agate mortar and pestle then passed through $2 \mathrm{~mm}$ stainless steel sieve. $6 \mathrm{~g}$ of each sieved sample was mixed with $1.35 \mathrm{~g}$ of binder material and then homogenized in a pulverizer. A mixture of sample and binder was homogenized, weighed and pressed at 12 tons into a pellet of $32 \mathrm{~mm}$ diameter using a die pellet maker.

\subsection{Sample Measurements}

The analysis of total metal concentrations in the pellets was performed using polarized Energy Dispersive X-ray Fluorescence (EDXRF) located at the Tanzania Atomic Energy Commission. In order to increase the sensitivity of excitation of elements (sodium to uranium), the EDXRF consisted of three targets namely: High Oriented Pure Graphite (HOPG) target for light elements from sodium to vanadium, Molybdenum secondary target for middle elements from chromium to zirconium and Praseodymium to uranium, and a Barkla Aluminium Oxide $\left(\mathrm{Al}_{2} \mathrm{O}_{3}\right)$ target for high energy elements from yttrium to cerium (Spectro, 2005). Each pellet was loaded into a cleaned sample holder and then was inserted in the X-ray excitation chamber. With the help of automatic sample changer system, irradiation of samples was performed by assigning a time-based programme controlled by an $\mathrm{x}$-lab Pro ${ }^{\mathrm{TM}}$ software package provided with the system. In this technique, when a sample pellet is irradiated with primary X-rays $\left(\mathrm{I}_{\mathrm{o}}\right)$, the X-rays absorbed by the sample to produce characteristic X-ray peaks $\left(\mathrm{I}_{\mathrm{i}}\right)$ of the $\mathrm{i}^{\text {th }}$ element in the sample according to the Fundamental Parameter (FP) approach defined by Equation 1 (Van Greiken \& Markowicz,1993).

$$
I_{i}=I_{0} G_{o}\left(\rho_{i} d\right) \eta\left(\frac{1-e^{-a q l}}{a \rho d}\right)
$$

Where $G_{o}\left(p_{i} d\right)$ is spectrometer's geometric constant, $\eta_{i}$ is the detection efficiency of the $i^{\text {th }}$ element and the term the bracket is a correction factor for the matrix effect.

A spectrum of characteristic X-ray peaks was detected by a $\mathrm{Si}(\mathrm{Li})$ detector, displayed and stored on the Multichannel Analyser (MCA). The intensity of $i^{\text {th }}$ element in each characteristic X-ray peak formed on the MCA was then estimated using $\mathrm{x}$-lab Pro $^{\mathrm{TM}}$ software package according to the FP approach to quantify total concentration of the $\mathrm{i}^{\text {th }}$ element in the sample. Heavy metals concentrations in the samples were measured in two parallel pellets. During irradiation, prior each sample change disposable vinyl gloves were worn to prevent contamination of the samples. The soil $\mathrm{pH}$ values was measured in a mixture of about $4 \mathrm{~g}$ of the soils in $10 \mathrm{~mL}$ of distilled water suspension using Hanna pH meter (model H19023C) (Radojevic \& Bashkin, 2006).and electrical conductivity was measured in a mixture of $1 \mathrm{~g}$ soil to $5 \mathrm{~mL}$ of distilled water suspension using a $\mathrm{HI}$ 9828 multi range conductivity with intelligent probe in the laboratory.

\subsection{Quality Control}

In order to evaluate the accuracy provided by the EDXRF technique, the Montana soil 2711A Standard Reference Material (SRM) obtained from National Institute of Standards and Technology, USA was also prepared and analysed under similar experimental conditions as the unknown samples. The concentrations determined in the SRM for each element were compared with certified values of the same element in a sample in order to establish the level of agreement between the measured and certified values. As shown in Table 1 for the elements investigated, the deviations between the measured and certified concentrations were within $\pm 8 \%$.

In addition, the binder material was prepared through the entire analytical procedure and was analyzed to determine if there was significant contamination or interference in the analysis process that could have led to the reporting of elevated metals concentrations. The analytical results of binder material indicated that there was not significant contamination or interference for each analyte. The limit of detection (LOD) for each element: Aluminum (Al), Iron (Fe), Lead ( $\mathrm{Pb}$ ), Magnesium (Mg), Arsenic (As), Cadmium (Cd), Chromium (Cr), Copper $(\mathrm{Cu})$, Manganese $(\mathrm{Mn})$, Mercury $(\mathrm{Hg})$, Nickel $(\mathrm{Ni})$ and Zinc $(\mathrm{Zn})$ was determined as shown in Table 1. 
Table 1. Comparison of measured and certified metal concentration levels of metals based on SRM, Montana-2711A and LOD by EDXRF

\begin{tabular}{lllll}
\hline Element & Certified value & $\begin{array}{l}\text { Measured } \\
\text { EDXRF results }\end{array}$ & $\begin{array}{c}\% \\
\text { Deviation }\end{array}$ & $\begin{array}{c}\text { LOD } \\
\left(\mathrm{mgkg}^{-1}\right)\end{array}$ \\
\hline $\mathrm{Al}(\%)$ & $6.72 \pm 0.06$ & $6.38 \pm 0.08$ & 5.06 & 20.00 \\
$\mathrm{Fe}(\%)$ & $2.82 \pm 0.04$ & $2.72 \pm 0.02$ & 3.55 & 5.00 \\
$\mathrm{~Pb}(\%)$ & $0.14 \pm 0.001$ & $0.15 \pm 0.09$ & -7.14 & 0.85 \\
$\mathrm{Mg}(\%)$ & $1.07 \pm 0.06$ & $1.16 \pm 0.06$ & -8.41 & 5.00 \\
$\mathrm{As}\left(\mathrm{mgkg}^{-1}\right)$ & $107.00 \pm 5.00$ & $109.04 \pm 6.01$ & -1.91 & 1.31 \\
$\mathrm{Cd}\left(\mathrm{mgkg}^{-1}\right)$ & $54.10 \pm 0.50$ & $56.44 \pm 1.00$ & -4.33 & 6.60 \\
$\mathrm{Cr}\left(\mathrm{mgkg}^{-1}\right)$ & $52.30 \pm 2.90$ & $50.41 \pm 1.00$ & 3.61 & 15.70 \\
$\mathrm{Co}\left(\mathrm{mgkg}^{-1}\right)$ & $9.89 \pm 0.18$ & $9.53 \pm 0.25$ & 3.64 & 21.70 \\
$\mathrm{Cu}\left(\mathrm{mgkg}^{-1}\right)$ & $140.00 \pm 2.00$ & $139.77 \pm 0.19$ & 0.16 & 1.79 \\
$\mathrm{Mn}\left(\mathrm{mgkg}^{-1}\right)$ & $675.00 \pm 18.00$ & $669.77 \pm 10.20$ & 0.77 & 14.10 \\
$\mathrm{Hg}\left(\mathrm{mgkg}^{-1}\right)$ & $7.42 \pm 0.18$ & $6.85 \pm 0.25$ & 7.68 & 0.94 \\
$\mathrm{Ni}\left(\mathrm{mgkg}^{-1}\right)$ & $21.70 \pm 0.70$ & $20.23 \pm 0.50$ & 6.77 & 2.70 \\
$\mathrm{Zn}\left(\mathrm{mgkg}^{-1}\right)$ & $414.00 \pm 11.00$ & $391.82 \pm 3.96$ & 5.36 & 1.35 \\
\hline
\end{tabular}

\section{Results}

Sample identity (ID), GPS coordinates of sampling locations shown in Fig 1, soil pH and electrical conductivity (EC) obtained are presented in Table 2. The minimum, maximum, average and median of metal concentrations in soil at depths $0-15$ and $15-30 \mathrm{~cm}$ obtained as described in 2.4 using equations 2 and the calculated correlation coefficients of metal concentrations are presented in Table 4.

Table 2. Plots or ID, $\mathrm{pH}$ and EC of soil and GPS (X and $\mathrm{Y}$ coordinates) for 42 sampling locations

\begin{tabular}{lllcc}
\hline Sample ID & X Coordinate & Y Coordinate & $\mathrm{pH}(\mathrm{unit})$ & $\mathrm{EC}\left(\mathrm{mScm}{ }^{-1}\right)$ \\
\hline BH5A & 37L0233126 & 8885087 & 5.7 & 8.2 \\
BH5B & $37 \mathrm{~L} 0233140$ & 8885367 & 5.7 & 8.7 \\
MRP14 & 37L0233182 & 8885255 & 6.3 & 7.2 \\
GWS1 & 37L0228061 & 8889395 & 7.6 & 6.4 \\
GWS2 & 37L0228139 & 8889582 & 7.8 & 6.4 \\
MRP23 & 37L0228199 & 8889639 & 7.5 & 7.0 \\
MBL2 & 37L0240380 & 8888047 & 6.2 & 6.6 \\
HDL2 & 37L0239796 & 8887938 & 7.4 & 6.9 \\
BH30 & 37L0239874 & 8887885 & 7.0 & 7.3 \\
MRP8 & 37L0239677 & 8887855 & 5.7 & 7.8 \\
MBL7 & 37L0236143 & 8891776 & 6.0 & 6.0 \\
MBL4 & 37L0237288 & 8892284 & 6.1 & 9.0 \\
MBL3 & 37L0235004 & 8888447 & 5.6 & 9.7 \\
MBL1 & 37L0234153 & 8889570 & 5.7 & 7.8 \\
MB2 & 37L0234000 & 8801002 & 6.0 & 7.3 \\
BH2B & 37L0232200 & 8890109 & 6.4 & 9.6 \\
MRP13 & 37L0232250 & 8890145 & 7.2 & 9.7 \\
HDL9 & 37L0228956 & 8888266 & 7.8 & 6.6
\end{tabular}




\begin{tabular}{|c|c|c|c|c|}
\hline HDL8 & 37L0227608 & 8887464 & 7.1 & 4.2 \\
\hline MBL8 & 37L0233602 & 8884984 & 6.2 & 9.1 \\
\hline $4 \mathrm{~A}$ & 37L0230319 & 8882798 & 6.2 & 8.6 \\
\hline MRP13 & 37L0230489 & 8882699 & 7.2 & 9.3 \\
\hline BH3 & 37L0235989 & 8881609 & 7.8 & 9.3 \\
\hline MBL7 & 37L0239012 & 8892878 & 6.7 & 5.1 \\
\hline MRP 15 & $37 \mathrm{~L} 0236080$ & 8881586 & 7.0 & 9.0 \\
\hline SW1U & 37L0232976 & 8880136 & 5.5 & 4.6 \\
\hline SW1D & 37L0232976 & 8880136 & 5.5 & 4.5 \\
\hline SW2U & 37L0229538 & 8877601 & 6.4 & 4.9 \\
\hline SW3U & 37L0227941 & 8874697 & 6.5 & 8.2 \\
\hline SW3D & 37L0227913 & 8875007 & 6.8 & 7.4 \\
\hline SW4U & 37L0223240 & 8867535 & 7.3 & 8.8 \\
\hline SW4D & 37L0213216 & 8867527 & 7.3 & 8.4 \\
\hline SW5U & 37L0209629 & 8861303 & 6.3 & 3.8 \\
\hline SW5D & 37L0209618 & 8861304 & 6.4 & 3.7 \\
\hline SW6U & 37L0206213 & 8860975 & 6.5 & 2.8 \\
\hline SW6D & 37L0209213 & 8860986 & 6.5 & 2.6 \\
\hline SW7U & 37L0207694 & 8860501 & 6.7 & 3.4 \\
\hline SW7D & 3710207700 & 8860559 & 6.5 & 3.8 \\
\hline HDL15 & 37L0239012 & 8892875 & 5.8 & 8.1 \\
\hline MBL5 & 37L0240397 & 8891490 & 7.1 & 7.0 \\
\hline MRP24 & 37L0240409 & 8891490 & 6.4 & 9.7 \\
\hline SW2D & 37L0229512 & 8877624 & 7.1 & 6.7 \\
\hline Median & & & 6.5 & 7.3 \\
\hline Average & & & $6.6 \pm 0.7$ & $6.9 \pm 2.1$ \\
\hline
\end{tabular}

The $\mathrm{pH}$ values presented in Table 2 vary from 5.5 to 7.8 with a minimum $\mathrm{pH}$ observed in two samples obtained in locations with IDs SW1D and SW1U and a maximum value in sample obtained at ID BH3. Generally, pH values were divided into three groups: weak acidic $\mathrm{pH} 5.5$ to 6.8 , neutral $\mathrm{pH} 6.9$ to 7.1 and weak alkaline $\mathrm{pH} 7.2$ to 7.8. As can be seen in the results, about $64 \%$ of the soil samples (BH5A, BH5B, MRP14, MBL2, MRP8, MBL1, MBL3, MBL4, MBL7, MBL8, 4A, BH2B, MB2, SW1U, SW2U, SW1D, SW3U, SW3D, SW5U, SW5D, SW6U, SW6D, SW7U, SW7D, HDL15 and MRP24) was weak acidic. About $12 \%$ of samples (BH30, HDL8, MRP15, MBL5 and SW2D) represented neutral $\mathrm{pH}$ and about $24 \%$ of soil samples (GWS1, GWS2, MRP23, HDL2, MRP13, HDL9, MRP13, BH3, SW4U and SW4D) accounted for weak alkaline. An overall mean pH of $\mathrm{pH} 6.6 \pm 0.7$ and median of 6.5 shows that soil at MRP is weak acidic. The median value of 6.5 is about $79 \%$ of the maximum recommended $\mathrm{pH}$ for normal soils in Tanzania (TBS, 2007). EC values in Table 2 varied gradually from a minimum of $2.6 \mathrm{mScm}^{-1}$ obtained at one location (ID: SW6D) while the maximum of $9.7 \mathrm{mScm}^{-1}$ was obtained in samples measured at three locations (IDs: MBL3, MRP24 \& MRP13). The mean and median EC were $6.9 \pm 2.1$ and $7.3 \mathrm{mScm}^{-1}$, respectively, are much lower than the $400 \mathrm{mScm}^{-1}$ reported for normal soil by Horneck et al., (2007) known to be associated with soil salinity detrimental to plant growth.

With the exception of $\mathrm{Al}, \mathrm{Mn}$ and Fe all the heavy metals whose measured concentrations are listed in Table 3 have association with uranium ore deposits. Therefore, knowledge of their concentrations and spatial distribution prior uranium mining can be useful baseline data to assess future pollution associated with uranium extraction. As seen in Table 3, with the exception of Cd, the difference of total concentrations of elements in soils obtained at different depths and locations are marginal. This means the observed concentrations have had little interference with contamination from outside and therefore serve as good baseline data. This feature reduces the need to increase sampling points to establish the baseline data for the proposed uranium mining project at 
Mkuju.

Arsenic concentrations at both depths and sampling locations were below detection limit of $1.31 \pm 0.98 \mathrm{mgkg}^{-1}$; therefore future detection above this value would have strong association with uranium mining activities. Analysis of the data using EDXRF showed a total metal concentration of 3570-19400 for Al, 15200-58600 Fe, 400-1400 Mn, 15.2-54.9 Cr, 13.5-51.0 Zn, 2.2-45.3 Pb, 2.1-37.3 Cd, 0.2-23.0 Hg, 1.8-25.1Cu, 2.1-22.7 Ni and $0.8-9.1 \mathrm{mgkg}^{-1}$ for Co. While the mean and maximum metal concentrations presented in Table 3 are below permissible levels recommended by the United State Environmental Protection Agency (USEPA), European Union (EU) and Tanzania Bureau of Standards (TBS) also shows the measured concentration values should serve as baseline data to be used as indicators when the uranium mining industry should take precaution to minimalize pollution.

Table 3. Mean, Standard Deviation (STD), Median, Minimum and Maximum concentrations of Elements obtained from 84 Soil Samples at two depths compared to Permissible Levels from USEPA, EU and TBS

\begin{tabular}{|c|c|c|c|c|c|c|c|c|c|c|c|c|}
\hline & Depth & $\mathrm{Al}^{*}$ & $\mathrm{Cr}$ & $\mathrm{Mn}^{*}$ & $\mathrm{Fe}^{*}$ & $\mathrm{Co}$ & $\mathrm{Ni}$ & $\mathrm{Cu}$ & $\mathrm{Zn}$ & $\mathrm{Cd}$ & $\mathrm{Hg}$ & $\mathrm{Pb}$ \\
\hline MEAN & $(\mathrm{cm})$ & 79.2 & 28.3 & 0.8 & 25.9 & 3.1 & 8.6 & 8.7 & 28.5 & 12.2 & 1.9 & 24.8 \\
\hline STD & $0-15$ & 17.2 & 6.8 & 0.2 & 7.5 & 1.8 & 3.9 & 3.1 & 7.6 & 6.1 & 3.8 & 8.2 \\
\hline MED & & 80.3 & 27.9 & 0.9 & 24.7 & 2.6 & 8.3 & 8.6 & 28.5 & 12.7 & 0.9 & 24.7 \\
\hline MIN & & 35.7 & 15.2 & 0.4 & 15.2 & 0.8 & 2.1 & 3.2 & 13.5 & 2.1 & 0.2 & 2.2 \\
\hline MAX & & 110.2 & 53.1 & 1.1 & 54.5 & 8.7 & 15.0 & 15.4 & 47.0 & 37.3 & 23.0 & 39.1 \\
\hline MEAN & $15-30$ & 89.1 & 33.8 & 0.9 & 30.1 & 4.9 & 10.3 & 11.3 & 32.9 & 15.2 & 1.9 & 25.6 \\
\hline STD & & 15.1 & 6.9 & 0.2 & 9.2 & 2.2 & 4.6 & 4.5 & 8.0 & 5.5 & 3.4 & 7.4 \\
\hline MED & & 87.3 & 32.5 & 0.9 & 29.0 & 4.5 & 10.8 & 10.8 & 32.1 & 14.8 & 1.1 & 24.8 \\
\hline MIN & & 47.9 & 19.0 & 0.4 & 16.4 & 1.1 & 2.1 & 1.8 & 19.0 & 3.4 & 0.2 & 2.6 \\
\hline MAX & & 119.4 & 54.9 & 1.4 & 58.6 & 9.1 & 22.7 & 25.1 & 51.0 & 36.8 & 20.6 & 45.2 \\
\hline MEAN & $0-30$ & 84.2 & 31.1 & 0.9 & 28.0 & 4.0 & 9.4 & 10.0 & 30.7 & 13.8 & 1.9 & 25.2 \\
\hline STD & & 17.0 & 7.4 & 0.2 & 8.7 & 2.3 & 4.4 & 4.1 & 8.2 & 6.0 & 3.6 & 7.8 \\
\hline MED & & 84.6 & 30.4 & 0.9 & 27.1 & 3.5 & 9.8 & 9.9 & 31.5 & 13.8 & 1.0 & 24.7 \\
\hline MIN & & 35.7 & 15.2 & 0.4 & 15.2 & 0.8 & 2.1 & 1.8 & 13.5 & 2.1 & 0.2 & 2.2 \\
\hline MAX & & 119.4 & 54.9 & 1.4 & 58.6 & 9.1 & 22.7 & 25.1 & 51.0 & 37.3 & 23.0 & 45.2 \\
\hline MEAN & World $^{1}$ & 71 & 100 & 0.6 & 38 & & 40 & 30 & 50 & 0.06 & 0.03 & 10 \\
\hline MIN & & 10 & 1 & 0.02 & 7 & & 500 & 2 & 10 & 0.01 & 0.01 & 2 \\
\hline MAX & & 300 & 1000 & 3.0 & 550 & & & 100 & 300 & 0.7 & 0.3 & 200 \\
\hline MAX & $\mathrm{TBS}^{2}$ & & & 1.5 & & & 100 & 200 & 150 & 1 & & 200 \\
\hline MAX & $\mathrm{EPA}^{3}$ & & 11 & & & & 72 & 270 & 1100 & 0.43 & & 200 \\
\hline EL & 1 & & & & 30 & & 3 & & 1 & ) & & \\
\hline
\end{tabular}

Note: *=multiplied by $10^{3} ; 1^{=}$(Vinogradov, 1959; Lindsay, 1979; Murthy, 2008); $2=($ TBS, 2007); 3=(USEPA, 2002); $4=(\mathrm{EU}, 2002)$.

\subsection{Correlation Analysis}

In principle, the concentrations of elements that occurred naturally have a certain association because of their common origin. Therefore knowledge of this association could be used as additional baseline data because subsequent pollution would distort the association. Since correlation is strong index this association, it was calculated for the concentration of all elements present in the samples (in achieves-too large to be presented) and the values obtained are presented in Table 4. 
Table 4. Correlation Coefficient of Concentration values of different Elements in 84 Soil Samples from Mkuju river Basin. Significantly at levels of $\alpha$ 0:05

\begin{tabular}{cccccccccccc}
\hline & $\mathrm{Al}$ & $\mathrm{Cr}$ & $\mathrm{Mn}$ & $\mathrm{Fe}$ & $\mathrm{Co}$ & $\mathrm{Ni}$ & $\mathrm{Cu}$ & $\mathrm{Zn}$ & $\mathrm{Cd}$ & $\mathrm{Hg}$ & $\mathrm{Pb}$ \\
\hline $\mathrm{Al}$ & 1 & & & & & & & & & & \\
$\mathrm{Cr}$ & 0.33 & 1 & & & & & & & & & \\
$\mathrm{Mn}$ & 0.28 & 0.21 & 1 & & & & & & & & \\
$\mathrm{Fe}$ & 0.31 & 0.21 & 0.22 & 1 & & & & & & & \\
$\mathrm{Co}$ & 0.08 & 0.28 & 0.10 & 0.29 & 1 & & & & & & \\
$\mathrm{Ni}$ & 0.40 & 0.41 & 0.13 & 0.62 & 0.31 & 1 & & & & & \\
$\mathrm{Cu}$ & 0.13 & 0.38 & 0.23 & 0.28 & 0.43 & 0.24 & 1 & & & & \\
$\mathrm{Zn}$ & 0.32 & 0.36 & 0.16 & 0.45 & 0.19 & 0.54 & 0.22 & 1 & & & \\
$\mathrm{Cd}$ & 0.11 & 0.06 & 0.18 & 0.15 & 0.34 & $0.09 *$ & 0.23 & 0.06 & 1 & & \\
$\mathrm{Hg}$ & 0.26 & 0.12 & $0.08^{*}$ & 0.34 & 0.27 & 0.13 & 0.01 & 0.41 & $0.05^{*}$ & 1 & \\
$\mathrm{~Pb}$ & $0.21^{*}$ & $0.12^{*}$ & 0.33 & $0.11^{*}$ & $0.07^{*}$ & $0.16^{*}$ & $0.16^{*}$ & $0.15^{*}$ & $0.18^{*}$ & $0.05^{*}$ & 1 \\
\hline Note: ${ }^{*}=$ negative correlation & & & & & & & & &
\end{tabular}

From this table, it is clear that the correlation of elemental concentrations could be grouped in three categories: high $(\mathrm{r}=$ above $0.4, \mathrm{p}<0.05)$, medium $(\mathrm{r}=$ positive but less than $0.4, \mathrm{p}<0.05)$ and low $(\mathrm{r}=$ negative values $)$. The elements in the first category include: $\mathrm{Cr}-\mathrm{Ni}, \mathrm{Cr}-\mathrm{Cu}, \mathrm{Cr}-\mathrm{Zn}, \mathrm{Zn}-\mathrm{Ni}, \mathrm{Zn}-\mathrm{Hg}, \mathrm{Fe}-\mathrm{Ni}, \mathrm{Cu}-\mathrm{Co}$ and $\mathrm{Fe}-\mathrm{Zn}$. The elements in the second category include: Al-Cr, Al-Mn, Al-Fe, Al-Co, Al-Cu, Al-Zn, Al-Cd, Al-Hg, Cr-Mn, $\mathrm{Cr}-\mathrm{Fe}, \mathrm{Cr}-\mathrm{Co}, \mathrm{Cr}-\mathrm{Cd}$, Cr-Hg, Mn-Fe, Mn-Co, Mn-Ni, Mn-Cu, Mn-Zn, Mn-Cd, Mn-Pb, Fe-Co, Fe-Cu, Fe-Cd, $\mathrm{Fe}-\mathrm{Hg}$, Co-Ni, Co-Zn, Co-Zn, Co-Cd, Co-Hg, Ni-Co, Ni-Hg, Cu-Zn and $\mathrm{Cu} \mathrm{Cd}$. Thus, future deviations of these correlations could be interpreted as being caused by pollution related to the mining of the Mkuju River Project.

\section{Discussion}

For a concentration value to serve as baseline data it has to have various features. It must represent the natural distribution elemental concentration of the area likely to be affected by the mining project and location of sampling points must be reproducible. In principle, establishment of baseline data for such a vast area, about $1300 \mathrm{~km}^{2}$ in this case, can be a very challenging undertaking because it requires an enormous amount of sampling points, sample transport, preparation and elemental concentration measurements. As described earlier, the first requirement was achieved by finding methods to reduce sampling points using clustering areas with similar soil profile and dose rate. The second one was achieved by assigning GPS to each sampling point.

Since most of the heavy metals are not radioactive, use of dose rate for clustering of similar elemental concentration has its limitations in achieving the first requirement. Assuming that during soil formation elements were uniformly distributed in the soil profile, subsequent variation of elemental concentration or retention in soil at different layers would strongly depend on soil texture. Therefore use of soil texture would be a better approach to achieve this requirement. In this study both dose rate and soil texture were used to reduce the number of samples, as indicated in Table 2, to demarcate the vast area into 42 sample plots identifiable using ID number with GPS reference for future reproducibility of sampling locations. From the minimum, maximum and mean concentration values obtained it is evident that the variations of concentration levels for adjacent plots were not radically different. This means the measured spatial distribution of elemental concentrations (in achieves) is a good representation of the current elemental distribution in the region. Therefore could serve as baseline data needed to assess future pollution that will be related to the uranium mining.

\section{Conclusion}

The aim of this study was to establish baseline reference data for 13 heavy metals in soils adjacent of the proposed Mkuju river uranium project for subsequent monitoring for compliance with best practices in uranium mining. Gradual variation of elemental concentration values in adjacent plots is a strong indication that the elemental concentration obtained before averaging is a good representative of the background elemental distribution of the area surrounding the planned uranium mining project and therefore can be used as baseline data. However, some of the observed features make concentrations of some elements better baseline data than others. Since the association of lead and copper to uranium mining is high and their mobility values in soil are 
low, the concentration levels of these elements form important baseline data for assessing future pollution by the uranium mining process. Moreover, implicit in high correlation between metals is indication of similar origins, degradation of correlation between zinc and mercury and nickel would be a strong indicator for pollution due to the future uranium mining process. The correlation between copper and cobalt serve similar purpose.

\section{Acknowledgement}

The authors would like to grateful acknowledge with sincere thanks to the Administration of the Uranium One for the permission granted to work at the Mkuju site and for the support provided by its staffs at the Mkuju site including provision of logistical facilitation for the field work. Also most thanks to the COSTECH for sponsoring one of the authors in the $\mathrm{PhD}$ study leading to this work, and the Tanzania Atomic Energy Commission for grating the study leave.

\section{References}

Cheng, W. D., Zhang, G., Yao, H., Wu, W., \& Xu, M. (2006). Genotypic and Environmental Variation in Cadmium, Chromium, Arsenic, Nickel and Lead concentration in Rice Grains. Department of Agronomy, Zhejiang University. Hangzhou 310029, China.

EU. (2002). European Union. Heavy Metals in Wastes, European Commission on Environment. Retrieved from http://ec.e uropa.eu/environment/waste/studies/pdf/heavy metals report.pdf

FAO. (1988). Food and Agriculture Organization Revised Legend of the FAO and UNESCO Soil Map of the World Soils Resources Report No. 60 FAO/UNESCO/ISRIC, Rome.

Holmes, N. S., \& Morawska, L. (2006). A Review of Dispersion Modeling and its Application to the Dispersion of Particles. An Overview of Different Dispersion Models. Available Atmospheric Environment, 40(30), 5902-5928. http://dx.doi.org/10.1016/j.atmosenv.2006.06.003

Horneck, D. S., Ellsworth, J. W., Hopkins, B. G., Sullivan, D. M., \& Stevens, R. G. (2007). Managing Salt Affected Soils for Crop Production. PNW 601-E. Oregon State University, University of Idaho. Washington State University.

Jintao, L., Cuicui, C., Xiuli, S., Yulan, H., \& Zhenhai, L. (2011). Assessment of Heavy Metal Pollution in Soil and Plants from Dunhua Sewage Irrigation Area. Int. J. Electrochem. Sci. 6, 5314-5324.

Lindsay, W. L. (1979). Chemical Equilibria in Soils. John Wiley \& Sons. New York.

Lokeshappa, B., Shivpuri, K., Tripathi, V., \& Dik shit, A. K. (2012). Assessment of Toxic Metals in Agricultural Produce. Food and Public Health, 2(1), 24-29. Retrieved from http://Journal.Sapub.org/fph

Marticorena, B., \& Bergametti, (1995). Modeling the Atmospheric Dust Cycle: 1. Design of a Soil Derived Dust Emission Scheme. J. Geophysical Research, 10, 16415-16430. http://dx.doi.org/10.1029/95JD00690

Ming, C., Lena, Q. M., \& Willie, G. H. (1999). Baseline Concentrations of 15 Trace Elements in Florida Surface Soil. J. Environmental Qual., 28(4), 1173-1181. http://dx.doi.org/10.2134/jeq1999.2841173x

Momodu, M. A., \& Anyakpra, C. A. (2010). Heavy metal contamination of groundwater: the surulere study. Research Journal of Environmental \& Earth Science, 2(1), 39-43.

MSL. (2011). Mkuju River Project Definitive Feasibility Study. Project Team Report, Tanzania.

Murthy, N. N. (2008). A Case Study of Soil Contamination at Katedan Industrial Area, Hyderabad. NGRI. Proc. Contaminated Groundwater Monitoring and Soil Assessment. 1-12. Hyderabad, India.

NRC. (1992). Nuclear Regulatory Commission NUREG/CR-5849. Manual for Conducting Radiological Surveys in Support of License Termination, US Nuclear Regulatory Commission, Washington, D. C.

Paquill, F., \& Smith, F. B. (1983). Atmospheric Diffusion, Study of the Dispersion of Windborne Material form Industrial and Other Sources, Ellis Horwood Ltd. Chichester, 435.

Radojevic, M., \& Bashkin, V. N. (2006). Practical Environmental Analysis (2nd ed.). RSC Publishing, UK. 147-170.

Santos-Santos, E., Yarto-Ramírez, M., Gavilán-García, I., Castro-Díaz J., Gavilán-García, A., Rosiles, R., Suárez, S., \& López-Villegas, T. (2006). Analysis of Arsenic, Lead and Mercury in Farming Areas with Mining Contaminated Soils at Zacatecas, Mexico. J. Mex. Chem. Soc., 50(2), 57-63.

Spectro. (2005). XRF Fundamentals, Ametek, Spectro Analytical Equipment.

Swenson, L. J., Dahnke, W. C., \& Patterson, D. D. (1984). Sampling for Soil Testing. North Dakota State 
University, Department of Soil Sciences, Res. Rep. No. 8.

TBS. (2007). Tanzania Bureau of Standards. Soil Quality Limits for Soil Contaminants in Habitat and Agriculture TZS 972:2007 (E).

Trichopoulos, D. (1997). Epidemiology of Cancer. In De Vita VT (Ed.), Cancer, Principles and Practice of Oncology (pp. 231-232). Lippincott Company, Philadelphia.

USEPA. (2002). Supplemental Guidance for Developing Soil Screening Levels for Superfund Sites. Office of Solid Waste and Emergency Response, Washington, D.C. Retrieved from http://www.epa.gov/superfund/health/conmedia/soil/index.htm

Van Greiken, R. E., \& Markowicz, A. A. (1993). A Handbook of X-ray Spectrometry. Marcel Dekker Inc, New York.

Vinogradov, A. P. (1959). The Geochemistry of Rare and Dispersed Hemical Elements in Soils (2nd ed.). Revised and enlarged: New York, Consultants Bureau Enterprises, 209.

\section{Copyrights}

Copyright for this article is retained by the author(s), with first publication rights granted to the journal.

This is an open-access article distributed under the terms and conditions of the Creative Commons Attribution license (http://creativecommons.org/licenses/by/3.0/). 